\title{
Penerapan Library AR.JS untuk Pembuatan Augmented Reality Sebagai Media Pembelajaran Pengenalan Hewan
}

\author{
Dimas Wahyu Wibowo, Pramana Yoga Saputra, Eka Larasati Amalia, dan Farida Ulfa
}

\begin{abstract}
Augemented Reality (AR) merupakan teknologi yang menggabungkan bedan maya 3D ke dalam dunia nyata dan dalam waktu nyata. Penelitian ini menggunakan teknologi AR ke dalam bentuk media pembelajaran pengenalan hewan unutk anak-anak. Aplikasi ini dirancang untuk memudahkan anak-anak dalam mengenal nama dan jenis hewan. AR dapat menyajkan pembelajaran yang interaktif, karena anakanak tidak hanya belajar secara teori namun mereka juga dapat melihat objek hewan secara 3D. Aplikasi ini dibuat menggunakan AFrame Dari hasil pengujian yang telah dilakukan, dapat disimpulkan bahwa aplikasi yang dibangun mampu menampilkan semua visualisasi objek 3D sehingga dapat digunakan untuk media pembelajaran.
\end{abstract}

Kata Kunci - Augemented Reality, Media Pembelajaran, Hewan.

\section{PENDAhuluan}

$\mathrm{B}$ elajar adalah semua aktivitas yang dilakukan seseorang sehingga menimbulkan perubahan tingkah laku berbeda ketika sebelum dan setelah belajar. Pada proses belajar mengajar diharapkan terdapat interaksi yang baik antara anak dan tenaga pendidik atau orang tua. Agar penyampaian materi dapat lebih menarik, maka metode pengajaran tidak hanya dengan menggunakan alat peraga secara konvensional tetapi dapat juga menggunakan teknologi komputer. Dengan mengikuti perkembangan teknologi informasi, metode pembelajaran dapat diubah menjadi lebih menarik dan interaktif. Salah satu perkembangan media pembelajaran yang saat ini masih baru adalah media pembelajaran dengan menggunakan Augmented Reality.

Augmented Reality (AR) merupakan sebuah teknologi yang menggabungkan benda maya tiga

${ }^{1}$ Dimas Wahyu Wibowo. Author is with the Information Technology Majors Malang State Polytechnic, Malang, Indonesia (corresponding author provide phone 0341-404424; email dimasw@polinema.ac..id)

${ }^{2}$ Pramana Yoga Saputra. Author is with the Information Technology Majors Malang State Polytechnic, Malang, Indonesia (corresponding author provide phone 0341-404424; email pramana.yoga@polinema.ac..id)

${ }^{3}$ Eka Larasati Amalia. Author is with the Information Technology Majors Malang State Polytechnic, Malang, Indonesia (corresponding author provide phone 0341-404424; email eka.larasati@polinema.ac..id)

${ }^{4}$ Farida Ulfa. Author is with the Information Technology Majors Malang State Polytechnic, Malang, Indonesia (corresponding author provide phone 0341-404424; email farida.ulfa@ polinema.ac..id) dimensi ke dalam lingkungan nyata dan menampilkannya dalam waktu nyata. Dengan adanya AR, penyampaian informasi lebih menarik dan nyata. Buku yang selama ini digunakan sebagai media pembelajaran dapat ditambah fungsinya dengan media AR yang akan menampilkan animasi 3D secara nyata pada perangkat mobile phone.

Pada penelitian ini dibuat media pembelajaran alternatif baru untuk mengenalkan objek benda kepada anak yang menggunakan teknologi AR. Dengan menggabungkan dunia nyata dan dapat merangsang imajinasi anak termotivasi untuk belajar.

\section{TINJAUAN PUSTAKA}

\subsection{Augmented Reality}

Augmented Reality (AR) atau juga dikenal dengan realitas tertambah adalah teknologi yang menggabungkan benda 2 atau 3 dimensi ke dalam waktu nyata (real time). Dengan adanya AR, lingkungan nyata di sekeliling kita dapat menjalankan interaksi dalam bentuk digital (virtual). Teknologi AR banyak digunakan pada dunia hiburan, kedokteran, militer, pendidikan, dan manufaktur. Ada beberapa Metode yang dapat digunakan untuk menampilkan AR yaitu:

- Marker AR (Marker Based Tracking)

Marker biasanya merupakan ilustrasi hitam dan putih persegi dengan batas hitam tebal dan latar belakang putih. Komputer akan mengenali posisi dan orientasi marker dan menciptakan dunia virtual 3D yaitu titik $(0,0,0)$ dan 3 sumbu yaitu X,Y,dan Z.

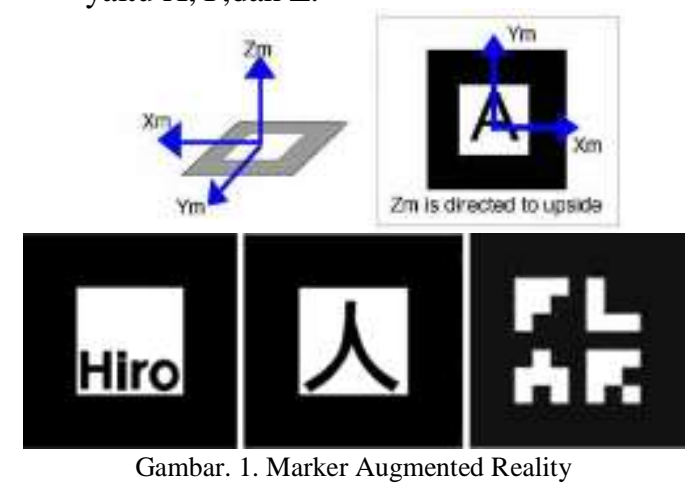

- Markerless AR

Dengan menggunakan metode ini, pengguna tidak perlu menggunakan sebuah marker untuk menampilkan objek digital. 


\section{GPS Based Tracking}

Dengan memanfaatkan fitur GPS dan kompas yang ada didalam smartphone, aplikasi akan mengambil data dari GPS dan kompas kemudian menampilkannya dalam bentuk arah yang kita inginkan secara realtime, bahkan ada beberapa aplikasi menampikannya dalam bentuk 3D.

\subsection{WebGL (Web Graphics Library)}

WebGL adalah teknologi web yang dapat menampilkan grafis 3D ke dalam browser tanpa memasang perangkat lunak tambahan. Web GL dapat digunakan untuk membuat game, Virtual Reality dan Augmented Reality. Khronos Group merilis spesifikasi WebGL 1.0 yang telah dikembangkan dan diuji. Dalam prakteknya, WebGL 1.0 mengkompilasi javascript dari OpenGL ES 2.0 API. API berfungsi untuk mengatur buffer vertex dan indeks, untuk mengubah kondisi rendering seperti textur atau mengubah matriks, dan untuk memanggil gambar sederhana.

WebGL merupakan standar baru untuk grafis 3D di Web. Dengan WebGL, pengembang dapat memanfaatkan kemampuan penuh dari hardware grafis dalam merender pada komputer hanya menggunakan Javascript, web browser, dan web standar teknologi yang cukup. Sebelum adanya WebGL, pengembang harus selalu bergantung pada plug-in atau aplikasi bawaan dan meminta penggunanya untuk mendownload dan menginstal perangkat lunak secara kustom untuk memberikan pengalaman 3D yang sesungguhnya. WebGL merupakan bagian dari keluarga teknologi HTML5. WebGL menjadi komponen penting dalam perangkaian mengubah peramban modern menjadi platform aplikasi dikelasnya.

\subsection{Graphic}

Grafik komputer 3 dimensi biasa disebut 3D atau adalah bentuk dari benda yang memiliki panjang, lebar, dan tinggi. Grafik 3 Dimensi merupakan teknik penggambaran yg berpatokan pada titik koordinat sumbu $x$ (datar), sumbu y(tegak), dan sumbu $z$ (miring). Representasi dari data geometrik 3 dimensi sebagai hasil dari pemrosesan dan pemberian efek cahaya terhadap grafika komputer 2D. Tiga Dimensi, biasanya digunakan dalam penanganan grafis. 3D secara umum merujuk pada kemampuan dari sebuah video card. Saat ini video card menggunakan variasi dari instruksiinstruksi yang ditanamkan dalam video card itu sendiri (bukan berasal dari software) untuk mencapai hasil grafik yang lebih realistis dalam memainkan game komputer. Grafik 3D merupakan perkembangan dari grafik 2D. Di dalam grafika komputer, 3D merupakan bentuk grafik yang menggunakan representasi data geometri tiga dimensi.

\subsection{A-FRAME}

A-Frame adalah teknologi baru dari Mozilla, yang memungkinkan Anda untuk membuat pengalaman 3D, Virtual Reality, Augmented Reality dan hanya dengan beberapa tag HTML. A-Frame Ini dibangun di atas WebGL, Three.js, dan beberapa Elemen Khusus, yang bagian dari standar Komponen HTML. Khususnya Untuk pengembangan Augmented Reality Jerome Etienne membuat sebuah library javascript dengan nama ar.js untuk mempermudah pembuatan Augmented reality. Untuk format objek yang digunakan atau support dengan library ar.js ini antara lain : gITF 2.0 and gITF, OBJ, COLLADA.

\section{5 glTF (GL Transmission Format)}

glTF (GL Transmission Format) merupakan format file untuk model 3D menggunakan standar JSON. Dikembangkan oleh Khronos Group. Oleh pengembangnya dideskripsikan sebagai "JPEG nya 3D". Pertama kali dikenalkan pada HTML5DevConf pada tahun 2016. Tujuan dikembangkannya gITF adalah untuk menyediakan sebuah format 3D yang efisien, bersifat interoperable untuk proses delivery nya, yang mampu mengompres ukuran 3D scene dan meminimasi proses runtime pada aplikasi dengan menggunakan WebGL dan API lain.

gITF dapat dimuat pada open source WebGL engines, termasuk Three.js, BabylonJS, Cesium, PEX, xeogl, dan A-Frame. Konverter open source untuk gITF yang tersedia antara lain COLLADA, FBX, dan OBJ. Untuk ekspor dan impor gITF dapat menggunakan Assimp. gITF bisa secara langsung diekspor dari aplikasi editor 3D seperti Blender, Autodesk 3ds Max, Autodesk Maya, Modo, Microsoft Paint 3D. Untuk open source glTF utility libraries dapat diprogram menggunakan bahasa JavaScript, Node.js, C++, C\#, Java, Go, Rust, Haxe, Ada, dan TypeScript. Daftar lengkap dari ekosistem gITF dikelola di gITF GitHub repo.

\section{Metode Penelitian}

\subsection{Analisa Kebutuhan}

Tahap ini menganalisis kebutuhan apa saja yang akan diperlukan dalam pembuatan aplikasi AR. Sehingga aplikasi AR ini nantinya dapat dijadikan sebagai alternatif belajar untuk siswa dalam membantu memahami materi tentang pengenalan hewan.

\subsection{Pengumpulan Data}

Tahap ini mengumpulkan data atau materi yang dijadikan sebagai acuan pembuatan aplikasi. Untuk objek kami mengambil dari https://sketchfab.com/ dan data objek berextensi .gltf (GL Transmission Format). Untuk data yang digunakan menggunakan model 3D.

\subsection{Uji coba dan implementasi}

Pada tahap ini akan dilakukan implementasi dan uji coba. Untuk proses uji coba kami menggunakan 13 contoh hewan antara lain burung hantu, lebah, bebek, kura-kura, macan, burung toucan, buaya, rabbit, paus biru, kepiting, gajah, panda dan jerapah. Dimana objekobjek tersebut dalam bentuk 3D dan dengan extensi .glTF. Selain uji coba menggunakan objek, peniliti pun melakukan uji coba pembuatan marker dan pengenalan marker sehingga objek dapat tampil pada web browser. 


\section{IMPLEMENTASI DAN UJI COBA}

Pada implementasi dan uji coba ini akan dilakukan antara lain : pembuatan marker dan pattern, menampilkan objek ke marker dan mengatur ukuran objek agar tidak tampil terlalu besar. Untuk pembuatan aplikasi ini menggunakan media browser untuk menampilkan objek 3D, bahasa pemograman yang digunakan HTML dan membutuhkan sebuah library untuk mengenali marker yang telah dibuat.

\subsection{Pembuatan Marker}

Dalam tahap pembuatan marker dan pattern dengan objek yang berbeda-beda sehingga menghasilkan marker dan pattern yang berbeda-beda. Untuk pembuatan marker menggunakan AR.Js Marker training dengan cara mengunggah image yang akan dijadikan sebagai marker. Beberapa contoh hasil dari pembuatan marker dengan menggunakan ar.js marker training seperti pada Tabel 1.

TABLE I

CONTOH HASIL DARI AR.JS MARKER TRAINING
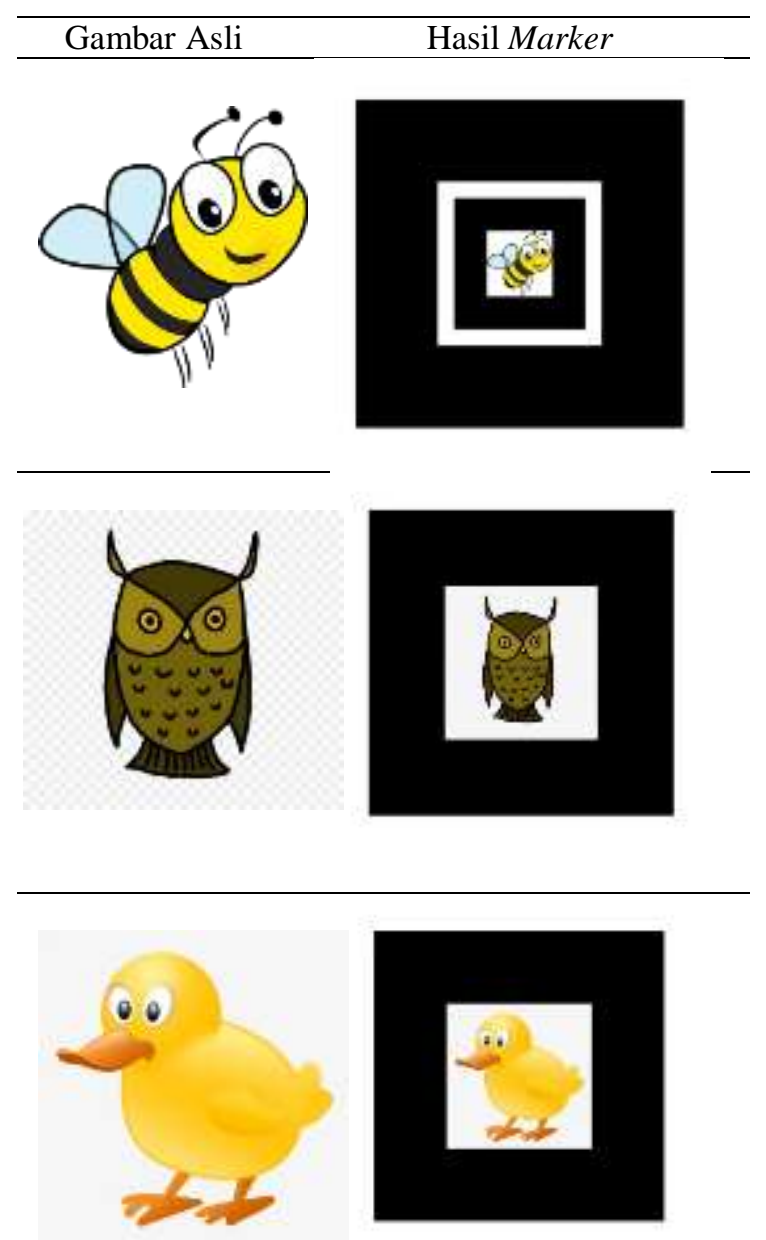

\subsection{Menampilkan Objek ke Marker}

Jika marker berhasil dibuat oleh Ar.js marker training maka selanjutnya adalah mengunduh pattern yang telah disediakan. Pattern tersebut merupakan pattern hasil dari image yang telah diunggah sebelumnya yang juga menghasilkan marker. Pada Gambar 3 merupakan contoh hasil pattern yang dihasilkan oleh ar.js marker generator.

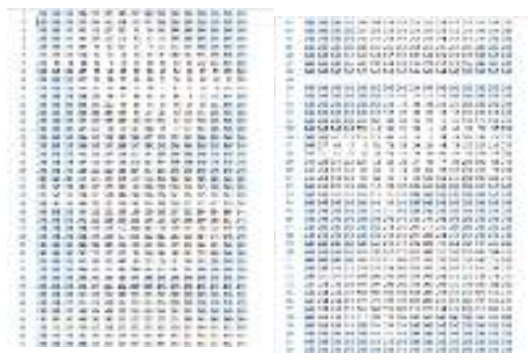

Gambar 2. Pattern yang dihasilkan ar.js marker generator

Pattern ini yang nanti digunakan untuk mengenali marker yang ditangkap oleh kamera. Sehingga pada saat marker ditangkap oleh kamera maka sistem akan menyesuaikan dengan pattern yang telah dibuat dan diset dalam kode. Jika sistem berhasil menyesuaikan pattern yang telah dibuat dan diset dengan marker-nya maka pada marker akan menampilkan objek yang dimaksud. Objek akan ditampilkan pada halaman browser. Untuk hasil dari objeknya dan marker yang digunakan seperti pada tabel 2 ..

TABLE II HASIL AUGMENTED REALITY

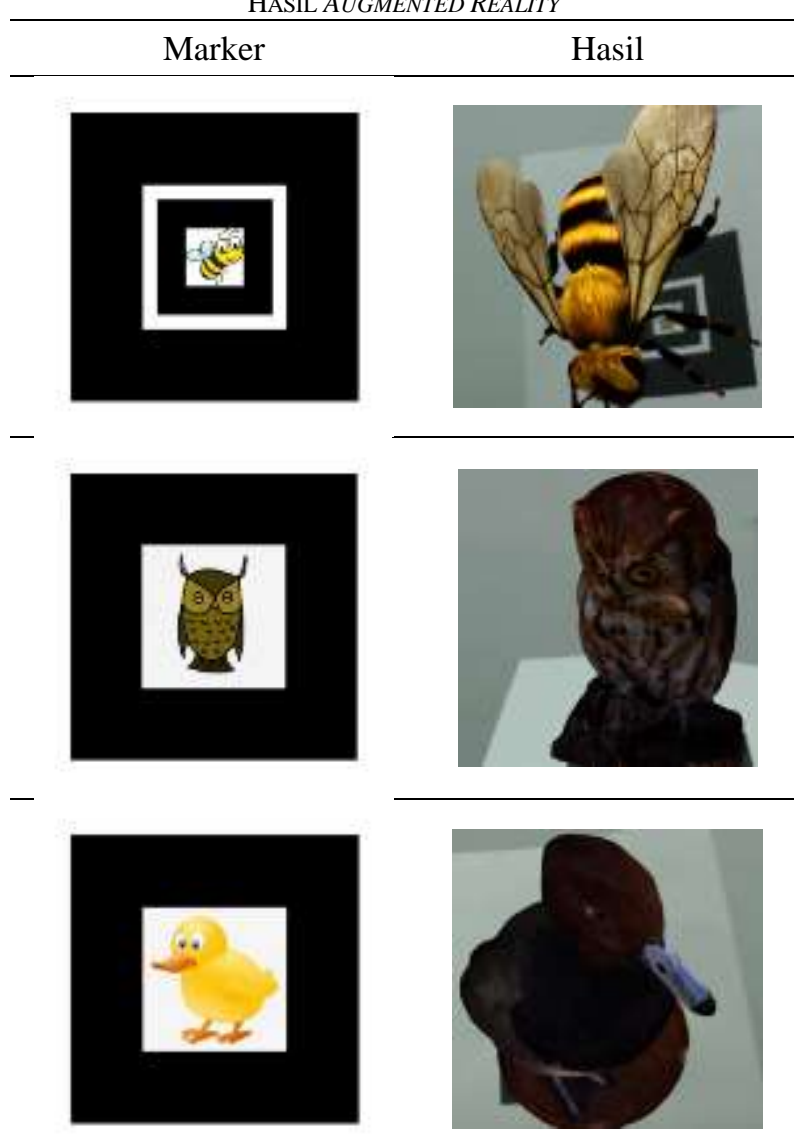

4.3 Mengatur Ukuran Objek

Pada saat pengujian ada beberapa objek hewan yang harus diatur dikarenakan objek yang tampil terlalu besar dan terlalu kecil. Untuk mengatur ukuran objek maka pada kode ditambahkan skala dengan sumbu x y z. Berikut ini tabel skala yang digunakan dalam penelitian ini. 
TABLE III

SKALA UKURAN OBJEK

\begin{tabular}{clccc}
\hline \multirow{2}{*}{ No } & Objek Hewan & \multicolumn{3}{c}{ Skala } \\
\cline { 3 - 5 } & & $\mathrm{X}$ & $\mathrm{Y}$ & $\mathrm{Z}$ \\
\hline 1 & Owl & 10 & 10 & 10 \\
2 & Bee & 0.09 & 0.09 & 0.09 \\
3 & Turtle & 0.01 & 0.01 & 0.01 \\
4 & Tiger & 0.01 & 0.01 & 0.01 \\
5 & Toucan Bird & 0.01 & 0.01 & 0.01 \\
6 & Crocodile & -1 & 1 & 1 \\
7 & Duck & 10 & 10 & 10 \\
8 & Rabbit & 0.02 & 0.02 & 0.02 \\
9 & Blue Whale & 0.5 & 0.5 & 0.5 \\
10 & Crab & 0.5 & 0.5 & 0.5 \\
11 & Elephant & 0.3 & 0.3 & 0.3 \\
12 & Panda & 0.3 & 0.3 & 0.3 \\
13 & Giraffe & 0.4 & 0.4 & 0.4
\end{tabular}

Setelah mengatur skala yang digunakan maka selanjutnya mengatur posisi x y z sehingga objek yang akan tampil dengan penanda sebuah box pada marker. Pada penelitian ini kamera yang bergerak akan menangkap kotak sebagai penanda dengan asumsi nilai $\mathrm{x}=0, \mathrm{y}=0.5$ dan $\mathrm{z}=0$.

\section{KESIMPULAN}

Berdasarkan hasil implementasi dan uji coba maka peneliti mendapatkan beberapa kesimpulan antara lain:

1. Untuk beberapa objek harus diatur ukurannya menggunakan scale dengan asumsi posisi box sebagai penanda adalah $\mathrm{x}=0, \mathrm{y}=0.5$ dan $\mathrm{z}=0$

2. Libary yang digunakan dapat menampilkan objek dalam bentuk 3D dan berextensi .glTF

3. Objek dapat ditampilkan dihalaman web browser mozila firefox versi 63.03 (64 bit)

Dengan kesimpulan diatas, aplikasi ini nantinya dapat digunakan untuk media pembelajaran pengenalan objek hewan dan dimana media pembelajaran augmented reality ini dapat di akses menggunakan web browser.

\section{PENGAKUAN}

Kami ingin mengucapkan terima kasih kepada Politeknik Negeri Malang dan Kantor Pusat Penelitian (P2M) yang telah mendukung proyek penelitian ini

\section{REFERENCES}

[1] Pembangunan Peta Kampus 3D Universitas Komputer Indonesia Berbasis Komputer. Jurnal Ilmiah Komputer \& Informatika

[2] Teguh, Kurniawan, Augmented Reality Sebagai Metafora Baru dalam Teknologi Interaksi Manusia dan Komputer, Jurnal Sistem Komputer, Vol 3 No 2, 2011

[3] Medium, 'arjs', 'Augmenting The Web Page',17 April 2017, <https://medium.com/arjs/augmenting-the-web-page e893f2d199b8> [accessed on 12 Novermber 2018]

[4] Medium,'arjs','How Create to you own marker?',7 Juni 2017, $<$ https://medium.com/arjs/how-to-create-your-own-marker 44becbec1105> [accessed on 15 Novermber 2018]

[5] Khronos, 'glTF','glTF Overview', < https://www.khronos.org/gltf/ $>$ [accessed on 20 November 2018]

[6] Tobias Blum, et al. 2012. An augmented reality magic mirror system for anatomy education. Institute of Electrical and Electronics Engineers Virtual Reality
[7] Tigala Maijarern, et al. 2018. Augmented realityb for science instructional media in primary school. International Conference on Digital Arts, Media and Technology

[8] Kurniawan Teguh dkk. 2017. Design of learning media for fish classification with augmented reality technology. International Conference on Information Technology, Computer, and Electrical Engineering (ICITACEE) 